\title{
La imaginación moral, o la ética como actividad imaginativa
}

\author{
Moral Imagination, or Ethics as an imaginative activity
}

BELÉN ALTUNA*

\begin{abstract}
Resumen: La expresión "imaginación moral” es cada vez más utilizada en la literatura filosófica. Lo que aquí se pretende es esclarecer el concepto y explicar cuáles pueden ser las funciones y aplicaciones de la imaginación en el ámbito moral. Para ello se parte de la definición que ofrece Ricoeur de la pretensión ética, como "deseo de una vida realizada, con y para los otros, en instituciones justas", y se desarrolla el papel de la imaginación en el cuidado de sí, el cuidado de los otros y el cuidado de las instituciones.

Palabras clave: imaginación, ética, adopción de perspectiva, empatía, sabiduría práctica, Paul Ricoeur.
\end{abstract}

\begin{abstract}
The expression "moral imagination" is increasingly used in the philosophical literature. Here I try to clarify this concept and explain what can be the functions and applications of the imagination in the moral area. To do so, my starting point is the definition that Ricoeur offers of the ethical aim as the "desire of an accomplished life, with and for others, within just institutions", and the role that imagination plays in the care of the self, the care of others and the care of the institutions.
\end{abstract}

Key-words: imagination, ethics, perspectivetaking, empathy, practical wisdom, Paul Ricoeur.

\section{Introducción}

Debes -es tu tarea- salvar el abismo existente entre tu capacidad de hacer y de imaginar: reducir el desnivel existente entre ambas capacidades; o, dicho de otro modo, debes ampliar considerablemente el limitado «ámbito de acción» de tu imaginación (y de tu capacidad de sentir, todavía más limitada), hasta que imaginación y sentimiento puedan captar y comprender la magnitud de lo que eres capaz de hacer; hasta que seas capaz de aceptar lo captado, o de rechazarlo. En una palabra: tu tarea consiste en ampliar tu imaginación moral. (Anders, 2010, 50; cursiva mía)

Las palabras de Günther Anders que encabezan estas líneas corresponden a los "Mandamientos de la era atómica" que escribió en 1957. Hacen referencia a ese sentimiento de

Recibido: 03/10/2016. Aceptado: 12/05/2017.

* Profesora agregada (contratada doctora) de Filosofía Moral en la Universidad del País Vasco (UPV-EHU). Correo: belen.altuna@ehu.eus. Líneas de investigación: empatía y sensibilidad moral, psicología moral, Emmanuel Levinas, Paul Ricoeur, ética narrativa, ética pública y de la administración. Publicaciones recientes significativas: 1) Una historia moral del rostro, Pre-Textos, Valencia, 2010; 2) "Empatía y moralidad: las dimensiones psicológicas y filosóficas de una relación compleja", Revista de Filosofía, Universidad Complutense, 2018 (en prensa). 
"obsolescencia del hombre" ante el poder de la técnica moderna, que abre unas desmesuradas posibilidades de acción a gran escala y a gran distancia. A la "moral de proximidad", que es la única que han conocido nuestros antepasados durante milenios, le sumamos ahora una "moral de larga distancia" cuyas consecuencias difícilmente podemos representar. Así, nuestra conciencia ha quedado desfasada: "podemos bombardear a cientos de miles, pero no llorarlos o sentir pesar por ellos", resume Anders. Sólo la imaginación podría salvar esa distancia física o temporal haciendo presente lo distante y sintiendo lo ausente, representando lo que nuestros sentidos no pueden ver ni abarcar. Años después, Hans Jonas se encargaría de desarrollar esa misma tesis, subrayando las nuevas dimensiones de la responsabilidad en la era técnica.

"Tu tarea consiste en ampliar tu imaginación moral". Lo cierto es que esa idea no ha tenido mucho predicamento en la historia de la filosofía y, de hecho, la expresión "imaginación moral" tampoco ha sido muy utilizada, al menos hasta tiempos recientes. El grueso de la tradición filosófica ha mirado más bien con desconfianza a la imaginación -relacionándola con la fantasía o arrinconándola en el campo de la creatividad artística-, y la mayoría no le ha otorgado un lugar en el razonamiento o el juicio morales. En la ensayística filosófica anglosajona contemporánea, en cambio, la expresión es cada vez más usada y, hasta cierto punto, teorizada, especialmente en autores ligados a la ética pragmatista y a la ética de la virtud ${ }^{1}$. Lo que no quiere decir que le den precisa o prioritariamente la misión que le otorga Anders.

En este artículo me propongo la difícil tarea de ensayar una visión de conjunto de lo que podría ser considerada la "imaginación moral", sintetizando la aportación de diferentes autores e inspirándome libremente en otros (como Paul Ricoeur). Analizaré cuáles pueden ser las funciones de la imaginación en la vida moral y cómo podríamos aplicarlas a los campos de la ética. Intentaré mostrar, en definitiva, en qué sentido podemos concebir la ética como una actividad imaginativa y en qué sentido es nuestra tarea, precisamente, "ampliar la imaginación moral”.

\section{Los vuelos de la imaginación moral}

\section{1. ¿Qué entendemos por imaginación? ¿Qué entendemos por moral?}

Comencemos con la imaginación misma. Dejando atrás esa desconfianza con la que ha sido vista a menudo en la tradición filosófica, en la actualidad las ciencias cognitivas y la

1 Desde la corriente pragmatista, es John Dewey el primero en subrayar la importancia de la imaginación para la moral, tal como recoge y amplia Steven Fesmire (2003); una tradición que ha seguido Richard Rorty (1996, 1997). Desde la ética de la virtud hay que señalar a Iris Murdoch (2001), a Martha Nussbaum (1997, 2005) o a John Kekes (1995, 2006b). Combinando distintas ciencias cognitivas y la filosofía contemporánea, es reseñable la aportación de Mark Johnson (1993), quien ya antes -junto con Lakoff (1986)- había mostrado la relevancia de las metáforas en nuestro pensamiento. Algunas visiones de síntesis sobre el papel de la imaginación en el razonamiento y la sensibilidad morales en Coeckelberg (2007), Chavel (2012) y, a mi juicio la más completa, Gibert (2014). Usos más específicos de la expresión “imaginación moral”: aplicada a la imaginación narrativa (además de en Nussbaum) en Himmelfarb (2007); aplicada a la resolución de conflictos, en Lederach (2007); aplicada a la ética de la empresa y de los negocios, en Werhane (1999); aplicada a casos de ética pública y de bioética, en McCollough (1991) y Stevens (1997). 
filosofía contemporánea -tanto la filosofía de la mente, como la filosofía de la psicología, la estética, la epistemología modal o la propia filosofía moral- la han convertido en un tema sustancioso de investigación y discusión ${ }^{2}$. Partamos, pues, de una definición contemporánea, la propuesta en la Standford Enciclopedia of Philosophy (Tamar Gendler, 2013):

Imaginar algo es formar una clase particular de representación mental de esa cosa. Imaginar se distingue típicamente de otros estados mentales como percibir, recordar o creer en que imaginar $\mathrm{S}$ no requiere (que el sujeto considere) que $\mathrm{S}$ sea el caso, mientras los demás estados sí lo requieren. Se distingue de otros estados mentales como desear o anticipar en que imaginar $\mathrm{S}$ no requiere que el sujeto desee o espere que $\mathrm{S}$ sea el caso, mientras los demás estados sí lo hacen.

Partiendo de esta definición, uno puede entender ya que no siempre se imagina con imágenes. De hecho, numerosos investigadores coinciden en esta distinción fundamental entre la imaginación perceptiva o sensorial, por una parte, basada en nuestra "imaginería mental"3 ("Imagino que llueve": visualizo mentalmente la lluvia que cae), y la imaginación proposicional, por otra, de contenido únicamente lingüístico ("Imagino que llueve": supongo que llueve, sin más $)^{4}$. La primera es parecida a las percepciones, la segunda a las creencias; aunque sin ser ni la una ni la otra, pues son actitudes cognitivas distintas. En definitiva, aunque la imaginación puede dar lugar a numerosas distinciones y taxonomías ${ }^{5}$, parece que todas ellas podrían agruparse en torno a la noción de "representación de posibilidades"', independientemente de que esas posibilidades sean de naturaleza perceptiva o proposicional, o una mezcla de ambas.

Y bien, ¿qué se quiere decir entonces cuando se habla de imaginación moral? Desde luego, no que la función de la imaginación sea siempre una función moral, o que sea siempre buena. Es claro que, como cualquier otra capacidad mental, como la racionalidad o la memoria, por ejemplo, puede ser usada con fines meramente instrumentales, o incluso con fines inmorales o perversos; amén de que la imaginación pueda ser desarrollada -como esa larga tradición le achaca- como mera fantasía o alejamiento lúdico o patológico de lo real.

2 Una visión histórica exhaustiva (de casi mil páginas) sobre las teorías de la imaginación en Brann (1991); algunos de los principales libros teóricos contemporáneos: Walton (1990); Currie/Ravenscroft (2002); McGinn (2004); una breve visión panorámica en Gendler (2013), y en Gibert, (2014).

3 La expresión "imaginería mental" designa el conjunto de representaciones internas que preservan los aspectos figurativos de los objetos, inscritas en la memoria, y que están disponibles en la rememoración, el sueño, la ensoñación y la imaginación perceptiva (cfr. Gibert, 2014, 40).

4 Otra forma de plantear esta distinción: imaginación proposicional (imaginar que P) e imaginación no proposicional, dividida ésta última en imaginación objetual (imaginar E) e imaginación activa (imaginar haciendo X) (Gendler, 2013).

5 Una de las distinciones más famosas es la de Kant, en la Crítica de la Razón Pura, entre imaginación reproductiva (que permite asociar libremente representaciones de la realidad derivadas de situaciones pasadas) y productiva (la facultad creativa del hombre). Una taxonomía más contemporánea (Currie/Ravenscroft, 2002) entre imaginación sensorial (experiencias parecidas a la percepción, pero sin los estímulos apropiados), imaginación creativa (combinación de ideas de maneras inesperadas o no convencionales) e imaginación recreativa (habilidad de experimentar o pensar el mundo desde una perspectiva distinta a la que presenta la experiencia).

6 Según McGinn (2004, 137); valorado también por Gibert $(2014,58)$. 
La mayoría de los autores que abogan por cultivar o ampliar nuestra "imaginación moral" entienden por lo tanto ese adjetivo, a mi juicio, de dos maneras diferentes aunque interconectadas:

a) El adjetivo 'moral' puede hacer referencia a la perspectiva y a los principios que guían esa exploración imaginaria: los temas u objetivos de la ética (como veremos en la II. Parte de este artículo).

b) El adjetivo 'moral' también puede hacer referencia a los efectos, a una supuesta consecuencia ética o moral de esa imaginación. Como mínimo, el efecto de una mejor comprensión moral de la situación, así como de una deliberación moral más afinada o sensible.

Muchas de las definiciones de "imaginación moral" que se proponen manejan ambas perspectivas, haciendo referencia siempre a un aumento de la visión, comprensión y sensibilidad morales. Por ejemplo: la "imaginación moral" es "la habilidad de discernir los aspectos morales implicados en una situación y de desarrollar una serie de soluciones alternativas a la situación desde una perspectiva moral" (Werhane, 1999, 5); o bien, puede entenderse como "la capacidad de empatizar con otros y de discernir posibilidades creativas para la acción ética" (McCollough, 1991, 16), o como la imaginación aplicada a "discernir lo que es moralmente relevante en cada situación, para entender empáticamente cómo entienden los otros las cosas y para afrontar la amplia serie de posibilidades que se abren ante nosotros en un caso particular" (Johnson, 1993, x).

\section{2. "Animales morales imaginativos"}

El estudio de las ciencias cognitivas de las últimas décadas y su comprensión de la teoría de los prototipos, la semántica de marcos (frame semantics), la estructura metafórica de gran parte de nuestro sistema conceptual, y el carácter narrativo de nuestra experiencia, ha llevado a Mark Johnson a defender que "los seres humanos son fundamentalmente animales morales imaginativos", "desde nuestros más mundanos y automáticos actos de percepción hasta nuestros más abstractas conceptualizaciones y razonamientos", y que, por tanto, "la cualidad de nuestra comprensión y deliberación moral depende crucialmente del cultivo de nuestra imaginación moral" $(1993,1)$.

Desde la fenomenología hermenéutica, Paul Ricoeur ya había desarrollado "la idea de imaginación como función general de lo posible práctico"7. Y es que, dejando ahora a un lado las aportaciones de las ciencias cognitivas, la mera fenomenología del actuar individual ya muestra con claridad ese papel decisivo de la imaginación: para empezar, explica Ricoeur, en el plano del proyecto, pues "en esa imaginación anticipatoria del actuar ensayo diversos cursos eventuales de acción y juego"; también en el plano de la motivación, pues la imaginación proporciona el medio "donde pueden compararse y medirse motivos tan heterogéneos como los deseos y las exigencias éticas, tan diversas como las reglas profesionales, las costumbres sociales o los valores fuertemente personales"; y, por último, en el

7 En "La imaginación en el discurso y la acción”, texto de 1976 recogido en el volumen de 2002 ( p. 207). 
plano mismo del hacer: "En lo imaginario ensayo mi poder de hacer, tomo la medida del yo puedo", me describo mi propia acción "con los rasgos de variaciones imaginativas sobre el tema del yo podría, incluso del yo hubiera podido de otra manera, si hubiera querido" (Ricoeur, 2012, 207).

Así expresado no cabe duda de que la ética, y toda la filosofía de la acción, la filosofía práctica en general, se sustenta en cierta medida en un plano imaginativo, es decir, despliega una racionalidad imaginativa (proposicional). Porque interpreta y valora sistemáticamente la realidad, porque critica y contrapone al es no sólo lo que podría ser, sino también lo que debería ser y lo que querríamos que fuera. Es decir, en gran medida funciona con contrafácticos, con posibilidades laterales, y conjuga esos tres verbos - poder ser, deber ser, querer ser- en un ejercicio a la par argumentativo e imaginativo.

En ese sentido se puede decir que toda ética es, en cierta forma, utópica. Como no podía ser de otra manera viniendo de esos "animales morales imaginativos" que somos, de ese homo utopicus, como sentenciara Ernst Bloch: un animal deseante, que sueña, fantasea, proyecta, imagina el "todavía no". Proyectar una irrealidad e intentar motivar para que se lleve a la acción, en eso consiste, precisamente y en gran parte, la ética ${ }^{8}$.

\subsection{Funciones de la imaginación en el ámbito moral}

Pero el rol de la imaginación en el ámbito de la moral no se reduce a ese papel de contraste o comparación (más o menos motivador, más o menos persuasivo) entre lo que hay y lo que debería, o podría, o querríamos que hubiera. Empecemos con ella, sí, pero distinguiendo también otras dos funciones igualmente importantes ${ }^{9}$ :

a) Representar y comparar las posibilidades de acción-individual y colectiva. Y evaluar, por supuesto, las consecuencias previsibles de cada una de ellas. Aunque pueda utilizarse también para replantear el pasado, implica sobre todo concebir los distintos presentes y futuros posibles. El principio de responsabilidad, para empezar, sería impracticable -o malamente practicable- sin esta capacidad de anticipar, ensayar y valorar las mejores formas y modalidades de acción ante una situación dada.

b) Representar y ver tal elemento de una situación como otra cosa. Como los propios Paul Ricoeur y Mark Johnson han mostrado magníficamente, nuestro pensamiento funciona a base de esquemas, metáforas, narrativas; tenemos una gran capacidad para ver algo como otra cosa, para enmarcarlo o reencuadrarlo de forma imaginativa (a veces de una manera sorprendentemente nueva: éste es el aspecto creativo de la imaginación que ha sido subrayado con tanta frecuencia). Los psicólogos nos recuerdan -como hace con deleite Paul Harris (2005)- que los niños juegan ya desde los dos años a hacer "como si", como que dan de comer a su muñeco, una representación en plástico de un bebé, o que juegan como si fueran papás y mamás, médicos y pacientes. Es desde luego una habilidad que no perdemos, sino que transformamos de múltiples maneras al hacernos mayores.

8 Como afirmaba Victoria Camps en La imaginación ética: "La ética nunca podría prescindir de la imaginación, tanto para urdir propuestas como para persuadir acerca de ellas" (1991, prólogo).

9 Me remito aquí a estos tres modos principales de "percepción moral imaginativa" (adopción de perspectiva, (re)encuadre y comparación), que distingue y estudia Gibert (2014). 
En general, nuestra percepción moral tiene que ver con la forma en que "encuadramos" una situación: así, no es lo mismo hablar del feto como un conjunto de células o como una persona, o referirse a un filete como mero alimento o como un animal muerto. De igual modo, podemos pensar en un refugiado sirio como un extraño potencialmente amenazante, o como un vecino nuestro que se ha quedado sin casa y sin lugar en el mundo. Es decir, podemos trasladar imaginativamente a los seres en consideración, o bien alejándolos o bien acercándolos a la esfera en que son permeables a nuestra empatía.

c) Representar y adoptar el punto de vista de otra(s) persona(s). Es esta función, estrechamente conectada con las anteriores, la que despierta tal vez un mayor entusiasmo en muchos autores: nuestra capacidad de ponernos en el lugar de otra persona, de imaginar cómo se siente, qué piensa, cuál es su visión del mundo o de una situación dada; es decir, nuestra capacidad de descentrarnos de nosotros mismos, de ponernos en la piel de otros y de "caminar un rato con sus zapatos" (como se dice en inglés).

Esta capacidad no es, sin más, empatía, aunque muchas veces se confunda con ella. Los psicólogos cognitivos y sociales prefieren emplear un término más específico, como es la adopción imaginativa de la perspectiva o del rol de otro (perspective-taking o role-taking): en primer lugar, una habilidad cognitiva imprescindible para las interacciones sociales, que nos hace conscientes de que la misma situación puede ser percibida e interpretada de manera diversa por la pluralidad de personas implicadas. Ello incluye también la capacidad de imaginar cómo nos ven o interpretan los demás y de prever cuáles podrán ser sus respectivas visiones o reacciones respecto a nosotros. Frente a la adopción de perspectiva fría o meramente cognitiva, la empatía sería una de las formas calientes más habituales, porque además de cognitiva es necesariamente afectiva: implica "compartir la emoción percibida en otro, sentir con otro" (Eisenberg/Strayer, 1992, 15), esto es, sentir una emoción congruente con la percibida o imaginada en el otro.

Una vez más, es claro que estas tres funciones o potencialidades de la imaginación ${ }^{10}$ no garantizan por sí solas que hagamos un uso moral, ético o prosocial de ellas. Como sentencia Solange Chavel $(2011,130)$ : "La imaginación sólo desarrolla nuestro sentido de lo posible, pero no contiene la llave del valor moral"; tiene un evidente valor epistémico -amplía el campo de lo posible, nos permite ver y experimentar el mundo y el punto de vista de otras personas de manera más rica y plural-, pero "la imaginación misma no crea nuestros conceptos ni nuestros principios morales", ni obliga a que los apliquemos en cierta dirección. De ahí el carácter definitorio del adjetivo 'moral'.

\section{La imaginación aplicada a los campos de la ética}

La mera imaginación no obliga la dirección o el sentido, en efecto. Pero pensemos cuáles pueden ser los efectos combinados de estas funciones de la imaginación en la dirección del

10 Rorty parecería referirse a todas estas funciones cuando afirma que la imaginación es "el bisturí de la evolución cultural", puesto que consiste en "la habilidad de redescribir lo familiar en términos no familiares" (1997, 100). Así lo harían los "poetas vigorosos" que re-encuadran bajo la luz de nuevas metáforas lo habitual nuestro "léxico último"-, desatascando el conflicto planteado. Pero Rorty entiende sobre todo el progreso moral como un incremento paulatino, mediante la imaginación (estimulada por novelas, etnografías, etc.), de nuestra sensibilidad a los detalles de sufrimiento y humillación de otras personas. 
impulso ético, cómo pueden enriquecer y afinar el razonamiento y la deliberación, el juicio y la acción morales. Para ello voy a partir de la que es, a mi juicio, una de las definiciones más abarcadoras y sugerentes de la pretensión ética, la desarrollada por Paul Ricoeur:

Deseo de una vida realizada -con y para los otros-en instituciones justas. Estos tres términos me parecen igual de importantes en la constitución ética de la persona ${ }^{11}$.

Como puede observarse, Ricoeur va más allá de la habitual división entre cuestiones de felicidad o vida buena y cuestiones de justicia, entre el enfoque teleológico/eudaimonístico y el deontológico. "La sabiduría práctica que buscamos tiende a conciliar la phrónesis de Aristóteles, a través de la Moralität de Kant y la Sittlichkeit de Hegel”, afirma (1996, 320). Un intento de integrar lo mejor de cada una de las perspectivas éticas, capitaneada, eso sí, por la herencia aristotélica, aunque bien temperada y encauzada por las otras ${ }^{12}$. "De la phrónesis retenemos que tiene como horizonte la «vida buena »; como mediación, la deliberación; como actor, el phrónimos, y como punto de aplicación, las situaciones singulares". Pero para que esa prudencia, ese hábito y esa destreza para deliberar bien ante una situación dada, pueda acercarse a la sabiduría práctica no ha de ser una phrónesis ingenua, aclara Ricoeur, sino una phrónesis crítica, la que incorpora también la obligación moral y el deber, pasa la prueba del imperativo de la universalidad y toma a cada persona como fin en sí misma. Aunque tampoco se detiene ahí, pues la phrónesis "en el juicio moral en situación" requiere constantemente de nuevos recursos y deliberaciones sensibles al contexto, abierta al "debate público, el coloquio amistoso, las convicciones compartidas" (1996, 320).

Ricoeur propone así una síntesis afortunada: que pensemos "en una única fórmula bien articulada el cuidado de sí, el cuidado del prójimo y el cuidado de la institución" $(2000,102)$. Esa división tripartita nos será de utilidad para observar con un poco más de detenimiento cómo funciona la imaginación en el ámbito moral. Eso sí, al hacerlo nos alejaremos en parte del propio Ricoeur, quien, a pesar de prestar una atención tan rica a la narración, la metáfora y la imaginación a lo largo de su extensa obra, no le otorga un lugar especialmente destacado en su "pequeña ética"13. Es difícil pensar, sin embargo, que esa sabiduría práctica que quiere impulsar pueda desarrollarse sin el cultivo de la imaginación moral.

11 Ricoeur $(2000,98)$. Procede del artículo "Aproximaciones a la persona", donde ofrece un buen resumen de la "pequeña ética” (según su expresión) que desarrolla largamente en los estudios 7, 8 y 9 de Sí mismo como otro (1990; 1996), basándose en la misma definición tripartita de la "intencionalidad ética" o "intuición inicial de la ética" $(1996,258)$.

12 La premisa de partida supone, por tanto, "la primacía de la ética sobre la moral", siempre y cuando se distingan estos dos términos de la manera en que él los hace, y no de la forma -es decir, básicamente como sinónimosen la que aparecen a lo largo del presente artículo: "por convención reservaré el término de ética para la intencionalidad (visée) de una vida realizada, y el de moral para la articulación de esta intencionalidad dentro de normas caracterizadas por la pretensión de universalidad y por un efecto de restricción" (Ricoeur, 1996, 174)

13 Lo que sigue, por tanto, es una elaboración propia, proyectando las diferentes funciones de la imaginación en cada una de las esferas éticas diferenciadas por Ricoeur. Para un estudio en profundidad del papel de la imaginación en la obra del filósofo francés: Etxeberria (1995); más brevemente y centrándose en el limitado uso de la "imaginación moral” en Ricoeur: Hunyadi (2009). 


\section{1. "Deseo de una vida realizada": imaginación para la felicidad/vida buena; imaginación para el cuidado de sí}

"Deseo de una vida realizada":

Inscribiendo así la ética en la profundidad del deseo, se remarca su carácter de aspiración, de optativo, anterior a todo imperativo. La fórmula completa sería: ¡Ojalá logre vivir bien, bajo el horizonte de una vida realizada y, en ese sentido, feliz! ${ }^{14} \mathrm{El}$ elemento ético de esta aspiración o de este deseo puede ser expresado por la noción de estima de sí mismo (Ricoeur, 2000, 98).

Pues bien, cómo no recordar aquella sentencia de Kant en la Fundamentación de la metafísica de las costumbres, donde afirmaba: "La felicidad es un ideal de la imaginación" (al contrario que el deber, dictado categóricamente por la razón pura práctica). Con ello quería subrayar su carácter empírico, contextual, volitivo y sentimental, imposible de dictaminar de manera universal. Y es que, para entender la vida buena y realizada, para dotarla de contenido, "no vale un pensar abstracto, tiene que ser concreto, conexo, complejo, imaginativo, circunstancial. Es decir, habría que recurrir a ejemplos en que la felicidad acontece"15, porque no a todos nos hacen felices las mismas cosas, ni de la misma manera.

Se necesita, pues, una imaginación concreta y particular, dado que los deseos y los proyectos, los límites y las posibilidades de cada persona pueden diferir de tal manera. John Kekes $(1995,2006$ b) ha estudiado la función central de la "imaginación moral" en la reflexión sobre cómo vivir una buena vida, entendida como una combinación de responsabilidad (lo que implica sensibilidad imaginativa para percibir cómo afectan nuestras acciones a los otros) y de realización (una satisfacción general con nuestra existencia, lo que supone una autointerpretación narrativa madura).

"La imaginación moral trabaja a través de la corrección, de la exploración, y de la disciplinada combinación de ambos", analiza Kekes (2006b). La imaginación correctiva se dirige a nuestro pasado, para descubrir en qué, cómo y por qué nos equivocamos. La exploradora mira al futuro y nos ayuda a tantear las posibilidades disponibles, así como a imaginar cómo nos sentiríamos de llevar a cabo cada una de esas opciones ${ }^{16}$. Ambas son interdependientes y su tarea entrelazada da lugar a la imaginación disciplinada, la que se centra en deliberar mejor sobre las posibilidades del presente.

Sin duda, el horizonte imaginativo de mucha gente es más bien chato: nace y vive en el seno de una tradición que le ofrece o le predetermina un marco de posibilidades convencio-

14 La formula recuerda a la insistencia de Nussbaum al referirse a la "imaginación eudaimonista" y a "la estructura fundamentalmente eudaimonista (aunque no egoísta) de nuestra imaginación y de nuestras preocupaciones más intensas" $(2008,430)$.

15 Julián Marías $(1998,59)$ La falta de imaginación, insiste Marías, es junto con el miedo uno de los principales obstáculos para la felicidad, y se lamenta de que "se enseña a multiplicar, a extraer raíces cuadradas, a nadar, a hacer deportes, pero no se enseña a imaginar, lo que sería fácil y tendría como consecuencia una prodigiosa dilatación de la vida" $(1998,208)$.

16 Cómo sería vivir conmigo mismo después de hacer lo que estoy planeando: ¿aprobaría a ese yo futuro? Un buen ejemplo de cómo ese tipo de imaginación puede estimular el coraje cívico en Ignatieff (2013). 
nales y una serie de roles que marcan sus aspiraciones y oportunidades. Su imaginación está enmarcada en esas limitadas directrices. Para darle alas, para ampliar sus posibilidades de vida buena, de florecimiento, ha de ser fecundada: eso es precisamente lo que puede hacer la literatura, la historia, la etnografía, el cine o la filosofía; toda la educación humanística, en definitiva, retratando vidas admirables y deplorables, perspectivas nuevas y diversas, ofreciendo las bases para el contraste y la comparación, tanto como para el ejemplo y la inspiración. Ese ensanchamiento de horizontes, ese fecundo laboratorio de posibilidades, será, no hace falta remarcarlo, igual de valioso para las dos pretensiones de la ética siguientes.

\section{2. "Con y para los otros": imaginación para la bondad/simpatía; imaginación para el cuidado del prójimo}

"Con y para los otros": "sugiero llamar solicitud a este movimiento de sí mismo hacia el otro, que responde a la interpelación de sí por el otro" (Ricoeur, 2000, 99). Es preciso aclarar que por "otro" entendemos tanto lo que aquí llama "prójimo" -es decir, el próximo, aquél con el que interactuamos, el tú de la interpelación, con nombre y rostro-, como, por otro lado, el "cada uno sin rostro" -es decir, el tercero, el conjunto de personas que no conocemos o no tratamos, todos aquellos que componen una comunidad o bien toda la humanidad-. Al hablar de solicitud, hablamos del tú, del prójimo/próximo, mientras que en el siguiente apartado hablaremos del "cualquier otro" anónimo, el "otro generalizado" (en la distinción de Benhabib ${ }^{17}$ ), enmarcado en nuestro deseo de instituciones justas que nos traten a todos con equidad.

Pero sigamos con Ricoeur: "la petición ética más profunda es la de la reciprocidad que instituye al otro como mi semejante y a mí mismo como el semejante del otro. Sin reciprocidad, o para emplear un concepto de raigambre hegeliana, sin reconocimiento, la alteridad no sería un otro distinto de sí mismo, sino la expresión de una distancia indiscernible de la ausencia. Hacer de otro mi semejante, tal es la pretensión de la ética en lo que concierne a la relación entre la estima de sí y la solicitud ${ }^{18 "}$ (2000:99). Es en la amistad -en la philia, tal y como la estudió Aristóteles- donde esa semejanza y esa reciprocidad se hacen más patentes, pero obviamente a menudo hay una disimetría de origen entre sí mismo y el otro, entre el

17 Benhabib utiliza la expresión 'otro generalizado' de manera sustancialmente diferente a G. H. Mead, quien lo usaba para expresar la voz de la sociedad o del grupo en nuestra imaginación. La distinción de Benhabib está más cercana al planteamiento de Ricoeur que estamos viendo (entre la solicitud por el "prójimo" otro concreto- y la petición de igualdad para "cada uno" -otro generalizado-): "El punto de vista del otro generalizado nos exige ver a todos y cada uno de los individuos como seres racionales a los que les corresponden los mismos derechos y deberes que quisiéramos atribuirnos a nosotros mismos. Al asumir este punto de vista, nos abstraemos de la individualidad y la identidad concreta del otro.(...) El punto de vista del otro concreto, en cambio, nos hace ver a cada ser racional como un individuo con una historia, identidad y constitución afectivo-emocional concreta. Al asumir este punto de vista nos abstraemos de lo que constituye lo común entre nosotros y nos centramos en la individualidad. Tratamos de entender las necesidades del otro, sus motivaciones, lo que busca y lo que desea" (Benhabib, 2006, 183).

18 Ricoeur afirma en más de un lugar, siguiendo la quinta de las Meditaciones cartesianas de Husserl, que la imaginación es la que permite articular el principio de analogía; esto es, que la noción de percepción analógica se apoya "en la de transferencia en imaginación. Decir que usted piensa como yo, que experimenta como yo, dolor y placer, es poder imaginar lo que yo pensaría y experimentaría si estuviera en su lugar" (2002, 210). 
agente y el paciente de la acción, dado que nos relacionamos siempre unos con otros desde una vulnerabilidad asimétrica. Así, como diría Levinas, no sólo somos seres que vivimos con otros, sino también para otros ${ }^{19}$. Es decir, siguiendo el impulso ético, para responder apropiadamente a la llamada de esa vulnerabilidad, de esos "rostros desnudos" que nos apelan o que necesitan de nosotros. Aquí estamos hablando de lo que Ricoeur llama "solicitud", de responsabilidad y cuidado de los otros, de simpatía, benevolencia, bondad, solidaridad.

Para todo ello es imprescindible afinar la sensibilidad para percibir, entender y sentir adecuadamente; sensibilidad para detectar y prever el daño moral (el que nos hacemos unos a otros), sensibilidad para tomar en consideración a todos los implicados e intentar ver la situación también desde el punto de vista de los demás. Es necesario, por tanto, un ejercicio de "descentramiento" que nos permite salir de nuestra visión egocéntrica y adoptar la perspectiva de otra(s) persona(s). Es la imaginación la que nos permite unir la información de que disponemos y desplazarnos a otra mente y a otra piel, a otra circunstancia y a otro contexto, recreándolos desde dentro.

Encontramos en la Ilustración escocesa una primera y clara reivindicación de la imaginación en este sentido, con el papel decisivo que otorga Hume (1740) a la simpatía (que hoy denominaríamos empatía) en la moralidad, y poco después Adam Smith (1759), entendiendo esa simpatía como una adopción de perspectiva imaginativa:

Como carecemos de la experiencia inmediata de lo que sienten las otras personas, no podemos hacernos ninguna idea de la manera en que se ven afectadas, salvo que pensemos cómo nos sentiríamos nosotros en su misma situación (...). La imaginación nos permite situarnos en su posición, concebir que padecemos los mismos tormentos, entrar por así decirlo en su cuerpo y llegar a ser en alguna medida una misma persona con él y formarnos así alguna idea de sus sensaciones, e incluso sentir algo parecido, aunque con una intensidad menor (Smith, 2004, 50).

En el Romanticismo, Shelley dejaría escrita esta sentencia memorable en su Defensa de la poesía (1840): "Un hombre para ser altamente bueno, ha de imaginar intensa y comprensivamente; ha de ponerse en el lugar de otro y de muchos otros; las penas y los goces de sus semejantes han de ser suyos. El gran instrumento del bien moral es la imaginación" (1986, 35). Esta idea sería después repetida en múltiples variantes, hasta llegar al estudio empírico y filosófico contemporáneo en torno a la empatía y sus conexiones -no necesariamente lineales y sencillas- con la conducta moral ${ }^{20}$. Recordemos que con empatía entendemos principalmente (más allá del mero contagio emocional, automático y prerreflexivo, que responde a una empatía especular o básica) una adopción de rol cognitiva-afectiva, caliente, como la expresada en las citas de Smith y Shelley.

19 Es clara la influencia de Lévinas en esta formulación de Ricoeur: Aristóteles, por ejemplo, aceptaría sin reservas ese con (los otros), pero no ese para, fuertemente levinasiano. Ahora bien, Ricoeur corrige también a Lévinas en algunos aspectos decisivos: si bien suscribe "completamente los análisis de Lévinas sobre el rostro, la exterioridad, la alteridad, esto es, el primado de la llamada procedente del otro sobre el reconocimiento de sí mismo por sí mismo" $(2000,99)$, no acepta, al contrario que aquél, que el otro siempre permanezca otro, infinito en su alteridad, y que no pueda verse como un semejante.

20 Me he dedicado a estudiar esas complejas conexiones de la empatía con la moralidad en Altuna (2018). 
Su correlato, la idea de que actuar mal, de manera irresponsable o causando daño a los demás, está relacionado no sólo con la falta de empatía, sino en general con la falta de imaginación moral, ha sido formulado igualmente con frecuencia. Recordemos cómo ejemplificaba Arendt (1999) "la banalidad del mal” en el oficial nazi Eichmann, caracterizándolo como un hombre incapaz de pensar más allá de los clichés e incapaz de ponerse en el lugar de los otros. Sin necesidad de acudir a un caso tan extremo, pensemos en las formas habituales en las que se hace daño -o no se evita un mal- por simple egocentrismo o estrechez de miras. Precisamente, si la "imaginación moral es el intento de valorar otros estilos de vida llegando a comprenderlos desde dentro tal como se les aparecen a aquellos que están activamente comprometidos con ellos", como afirma Kekes (2006a, 350), su cultivo será determinante para evitar esos casos -estos sí- tan "banales": "Al aumentar el conocimiento de uno mismo, al presentar opciones atractivas frente a la realización del mal, y al proporcionar una base para la comparación, el contraste y la crítica de la propia manera de ser y actuar, la imaginación moral ayuda a evitar las falsificaciones implicadas necesariamente en el hacer el mal de manera no intencional" (2006a, 354).

\section{3. "En instituciones justas": imaginación para la justicia/utopía; imaginación para el cuidado de las instituciones}

Deseo de vivir "en instituciones justas": "Introduciendo el concepto de institución, introduzco una relación con el otro que no se deja reconstruir sobre el modelo de la amistad". Así, concebimos ahora al otro como "el cada uno de una distribución justa", el tercero que no es el tú con el que interactuamos, sino la pluralidad de las personas que nos son anónimas; y por institución entendemos "la estructura del vivir-juntos de una comunidad", caracterizada por "un esquema de distribución, donde lo que se distribuye no son solamente bienes y mercancías, sino derechos y deberes, obligaciones y cargas, ventajas y desventajas, responsabilidades y honores" (Ricoeur, 2000, 100).

Hasta ahora habíamos aplicado la imaginación a los otros concretos con los que tenemos una relación personalizada, y a los que podemos imaginar con sus rasgos singulares y específicos. Pero nuestro círculo moral no se detiene en ese conjunto de conocidos, sino que se extiende más allá, hasta abarcar potencialmente a todos nuestros conciudadanos, o más allá, a todos los habitantes del mundo, puede que incluso al resto de animales y a las generaciones futuras, cuyo cuidado podríamos asimismo incluir en el círculo de nuestras preocupaciones éticas.

Aquí la "imaginación moral" se puede aplicar de varias formas: en primer lugar, y quizá la más evidente, en su dimensión exploratoria o contrafáctica, especialmente en su dimensión utópica. La proyección de sociedades imaginarias más justas, igualitarias, libres y habitables ha sido, es y será un estímulo fundamental de todo el pensamiento político-moral ${ }^{21}$.

21 Con la noción de "imaginario social", Ricoeur nos recuerda que los humanos usamos prácticas imaginativas para urdir toda identidad social y, siguiendo en parte a Mannheim, que la ideología no es una práctica menos imaginativa que la utopía. La ideología "parece vinculada a la necesidad, de un grupo cualquiera, de darse una imagen de sí mismo, de representarse, en el sentido teatral de la palabra, de ponerse en juego y en escena" (2002, 212). La utopía, por su parte, es el proyecto imaginario de otra sociedad, de otra realidad, una "imaginación constitutiva" que puede justificar, como la propia ideología, las opciones más opuestas. Si la 
Desde la República de Platón no hemos dejado de esbozar y proyectar una sociedad mejor, con instituciones y leyes más justas. Es claro el papel de la imaginación en el pensamiento explícitamente utópico, pero recordemos que las teorías contractualistas de la justicia se han levantado igualmente sobre ejercicios imaginativos, como el del "estado de naturaleza" o, en Rawls, la "posición original" con su "velo de la ignorancia".

Pero más allá de la representación y valoración de posibilidades de acción u organización institucional o colectiva, lo que las teorías de justicia contemporáneas de inspiración kantiana comparten - al centrarse en el procedimiento- es la idea de la "adopción ideal de roles". Es decir, otorgan un lugar epistémico decisivo a la toma de perspectiva fría (no empática, desde el momento en que perciben a ésta como sentimental y potencialmente distorsionadora) para las justificaciones racionales y los juicios morales imparciales. Así, Habermas parte de la "intuición fundamental" que está en la base del imperativo categórico kantiano: "desde el punto de vista moral se tiene que poder comprobar si una norma o modo de actuar podría encontrar en el círculo de los afectados una aquiescencia universal, motivada racionalmente y por lo tanto no obtenida mediante coacción alguna" $(2000,60)$. Y ello se realiza en un discurso práctico que "se puede entender como un proceso de entendimiento mutuo que por su forma propia insta a todos los implicados simultáneamente a la asunción ideal de roles" $(2000,18)$. Es decir, todos los afectados deberían ponerse imaginativamente en el lugar de los demás, ver la situación desde esa pluralidad de perspectivas y buscar desde esa comprensión compleja el mejor argumento. Por supuesto, esto funcionaría como ideal normativo: cuánto más se le aproximase el procedimiento real, tanto más justo sería el resultado.

Esta pretensión de "vivir en instituciones justas" nos lleva necesariamente a la dimensión política del ethos. Arendt, en la misma línea que la planteada arriba por Habermas, ligó el (buen) juicio político con el "pensamiento ampliado" (o la "capacidad de pensar en el lugar de cualquier otro"), siguiendo la idea que tomó de la Critica del Juicio de Kant. Y como ella subrayó, la sabiduría práctica ligada a esta capacidad se basa en la imaginación:

El pensamiento político es representativo; me formo una opinión tras considerar determinado tema desde diversos puntos de vista, recordando los criterios de los están ausentes; es decir, los represento. (...) Cuantos más puntos de vista diversos tenga yo presentes cuando estoy valorando determinado asunto, y cuanto mejor pueda imaginarme cómo sentiría y pensaría si estuviera en el lugar de otros, tanto más fuerte será mi capacidad de pensamiento representativo y más válidas mis conclusiones, mi opinión (Arendt, 2003, 369).

En otras palabras, pensar desde la perspectiva de todos los demás implicados es saber escuchar lo que ellos dicen, sin duda, pero también, cuando las voces de los demás están ausentes, imaginar para uno mismo una conversación con esos otros como compañeros de diálogo. La pluralidad irreductible de seres, opiniones, perspectivas e intereses convierte a esta habilidad imaginativa, bajo el deseo ético que la impulsa y la mantiene (el deseo de

función primaria de la ideología es la integración social, "la legitimación del sistema dado de autoridad", la de la utopía, como contrapunto, es la de subversión social. En realidad, ambas se implican dialécticamente, pues muestran "el juego de dos direcciones fundamentales del imaginario social" (2002, 216). 
una vida plena, con y para los otros, en el marco de instituciones justas), en un componente esencial, imprescindible, de la phrónesis crítica, la sabiduría práctica que buscamos para poder llevar a cabo con cierto éxito ese deseo.

\subsection{En definitiva, la ética como actividad imaginativa}

Es claro que la ética, ni entendiéndola como filosofía moral, ni como "intencionalidad de una vida realizada" es una actividad puramente imaginativa. Pero es también -y de una manera más intensa y más rica de lo que ha reconocido la gran tradición filosófica- imaginativa.

He intentado explicar que la imaginación es una facultad que va mucho más allá de la práctica fantasiosa o de la habilidad artística o innovadora a la que habitualmente ha sido relegada. Así, he expuesto que la comprensión moral de una situación y el juicio o la conducta que le siguen tienen mucho que ver con el uso que hagamos de esa imaginación. Cedo ahora la palabra, una vez más, a Hannah Arendt, para que nos recuerde en qué consiste su poder:

Sólo la imaginación nos permite ver las cosas con su verdadero aspecto, poner aquello que está demasiado cerca de una determinada distancia de tal forma que podamos verlo y comprenderlo sin parcialidad ni prejuicio, colmar el abismo que nos separa de aquello que está demasiado lejos y verlo como si nos fuera familiar. Esta «distanciación» de algunas cosas y este tender puentes hacia otras, forma parte del diálogo establecido por la comprensión con ellas; la sola experiencia instaura un contacto demasiado estrecho y el puro conocimiento erige barreras artificiales (...). Sin este tipo de imaginación, que en realidad es la comprensión, no seríamos capaces de orientarnos en el mundo. Es la única brújula interna de la que disponemos (1998, 45-46).

Aquí Arendt invoca el evidente valor epistémico de la imaginación, esa "brújula interna", pero todavía no le otorga una clara función moral. Curiosamente, sin embargo, habíamos comenzado este artículo con el que fuera su primer marido, Günther Anders, y su exhortación de que nuestra tarea consiste en ampliar nuestra "imaginación moral”. Más aún -nos recordaba- en esta era hipertecnológica en la que puede haber una distancia descomunal, espacial y temporal, entre los agentes de una acción y los pacientes que sufrirán sus consecuencias; una época en la que no dejan de sumarse facilidades para la práctica del viejo refrán "ojos que no ven, corazón que no siente". Frente a esa tendencia a la anestesia moral, se levanta un imperativo ético: imaginar y representarse los efectos lejanos o colaterales que nuestro multiplicado poder hacer puede producir, extremar las precauciones y afinar el cuidado.

El alegato de Anders es inspirador y apunta a cuestiones tremendamente importantes, pero a lo largo de esta exposición he defendido un concepto de imaginación moral más amplio aún que el propuesto por él. He sostenido que podríamos considerar "imaginación moral" ese uso de la imaginación que nos permite aplicar sus funciones principales -representar y comparar las posibilidades de acción (y el impacto de sus consecuencias), representar y ver tal elemento de una situación como otra cosa, representar y adoptar el punto 
de vista de otra persona- en pos del objetivo ético de un mejor cuidado de uno mismo, de un mejor cuidado de los otros, y de un mejor cuidado de las instituciones. Espero que esta breve defensa sea suficiente para entender que ninguna sabiduría práctica es imaginable, valga la redundancia, sin el cultivo y la maduración de esa facultad.

\section{Referencias}

Altuna, B. (2018), "Empatía y moralidad: las dimensiones psicológicas y filosóficas de una relación compleja”, Revista de Filosofía, Universidad Complutense, Madrid. Vol. 43, $\mathrm{n}^{\mathrm{0}} 2$ (en prensa).

Anders, G. (2010), Más allá de los límites de la conciencia, Barcelona, Paidós.

Arendt, H. (1998), De la historia a la acción, Barcelona, Paidós.

Arendt, H. (1999), Eichmann en Jerusalén, Barcelona, Lumen.

Arendt, H. (2003), Entre el pasado y el futuro, Barcelona, Península.

Benhabib, S. (2006), El Ser y el Otro en la ética contemporánea. Feminismo, comunitarismo y posmodernismo, Gedisa.

Brann, E. (1986), The World of Imagination, University of Chicago Press.

Camps, V. (1991), La imaginación ética (1983), Barcelona, Ariel.

Chavel, S. (2012): Se mettre à la place d'autrui. L'imagination moral, Press Universitaires de Rennes.

Coeckelberg, M. (2007), Imagination and Principles. An Essay on the Role of Imagination in Moral Reasoning, Palgrave.

Currie, G. / Ravenscroft, I. (2002), Recreative Minds. Imagination in Philosophy and Psychologie, Oxford, Clarendon Press.

Eisenberg, N. / Strayer, J., (1992), La empatía y su desarrollo, Bilbao, Desclée de Brower.

Etxeberria, X. (1995), Imaginario y derechos humanos desde Paul Ricoeur, Bilbao, Desclée de Brouwer.

Fesmire, S. (2003), John Dewey and Moral Imagination: Pragmatism in Ethics, Indiana University Press.

Gendler, T. (2013), "Imagination", The Standford Enciclopedia of Philosophy (Fall 2013 Edition).

Gibert, M. (2014), L'imagination en morale, Paris, Hermann.

Habermas, J. (2000), Aclaraciones a la ética del discurso, Madrid, Trotta.

Harris, P. (2005), El funcionamiento de la imaginación, México, FCE.

Himmelfarb, G. (2007), The Moral Imagination, Souvenir Press Ltd.

Hunyadi, M. (2009), "La force oubliée de l'imagination morale”, Laval théologique et philosophique, vol. $65, \mathrm{n}^{\circ} 3$.

Ignatieff, M. (2013), "Civil Courage and the Moral Imagination", Holanda, Universiteit Leiden.

Johnson, M. (1993), Moral imagination. Implications of Cognitive Science for Ethics, University of Chicago Press.

Kekes, J. (1995), Moral wisdom and good lives, New York, Cornell University Press.

Kekes, J. (2006a), Las raíces del mal, Buenos Aires, El Ateneo. 
Kekes, J. (2006b), The enlargement of life. Moral imagination at work, New York, Cornell University Press.

Lakoff, G. / Johnson, M. (1986), Metáforas de la vida cotidiana, Madrid, Cátedra.

Lederach, J. P. (2007), La imaginación moral. El arte y el alma de construir la paz, Bakeaz Gernika gogoratuz/ Red Gernika.

McCollough, T. (1991), The moral imagination and public life: raising the ethical question, NJ, Chatham House Studies.

McGinn, C. (2004), Mindsight: Image, Dream, Meaning, Harvard University Press.

Marías, J. (1998), La felicidad humana, Madrid, Alianza Universidad.

Murdoch, I. (2001), La soberanía del bien, Madrid, Caparrós.

Murdoch, I. (2013), "La ética y la imaginación”, Daimon, nº 60, 23-35.

Nichols, S. (ed.) (2006), The Architecture of the Imagination: New Essays on Pretence, Posibility, and Fiction, Clarendon Press.

Nussbaum, M. (1997), Justicia poética. La imaginación literaria y la vida pública, Andrés Bello.

Nussbaum, M. (2005), El conocimiento del amor. Ensayos sobre filosofía y literatura, Madrid, Antonio Machado.

Nussbaum, M. (2008), Paisajes del pensamiento. La inteligencia de las emociones, Barcelona, Paidós.

Ricoeur, P. (1989), Ideología y utopía, Madrid, Gedisa.

Ricoeur, P. (1996), Sí mismo como otro, Madrid, Siglo XXI.

Ricoeur, P. (2000), Amor y justicia, Madrid, Caparrós.

Ricoeur, P. (2002), Del texto a la acción, FCE.

Rorty, R. (1996), Contingencia, ironía y solidaridad, Barcelona, Paidós.

Rorty, R. (1997), ¿Esperanza o conocimiento? Una introducción al pragmatismo, Buenos Aires, FCE.

Shelley (1986), Defensa de la poesía, Barcelona, Península,

Smith, A. (2004), La teoría de los sentimientos morales (1759), Madrid, Alianza.

Stevens, E. (1997), Developing Moral Imagination. Case Studies in practical morality, $\mathrm{R} \& \mathrm{C}$.

Walton, K. (1990), Mimesis as Make-Beliefe, Cambridge, MA., Harvard University Press.

Werhane, P. H. (1999), Moral Imagination and Management Decision Making, New York, Oxford University Press. 
